\title{
Aspects regarding the use of ultrasounds in the food industry
}

\author{
Cristian Marian Sorică ${ }^{1 *}$, Marian Vintilă${ }^{2}$, Laurentiu Vlădutoiu ${ }^{1}$ Elena Sorică ${ }^{1}$, \\ Iulia Andreea Grigore ${ }^{1}$ and Mario Cristea ${ }^{1}$ \\ ${ }^{1}$ National Institute of Research - Development for Machines and Installations Designed to \\ Agriculture and Food Industry - INMA, Ion Ionescu de la Brad no. 6 Blvd., sector 1, Bucharest, \\ Romania \\ ${ }^{2}$ The Institute of Research and Development for Industrialization and Marketing of Horticultural \\ Products - ICDIMPH Horting, Drumul Gilăului no. 5N, sector 4, Bucharest, Romania
}

\begin{abstract}
Ultrasound is a rapidly developping research field that is more and more used in the food domain, both for analysis and processing of food products. This technology has been successfully applied within food industry for various processes like freezing, filtration, drying, separation, emulsion, sterilization and extraction. The paper presents aspects regarding the mechanism and use of ultrasound in food processing, as well as some technical equipment that use ultrasound within a combined technology, for the decontamination of the external surfaces of some horticultural products.
\end{abstract}

\section{Introduction}

Minimal processing of foods is defined as a trend to replace classical heat treatment processes with new, athermal processes, including new, milder heat processes.

The food industry is experiencing a strong development and has at its disposal a number of methods and techniques for the food processing [1].

The most important methods of athermal processing are:

- processing using high pressures;

- processing with supercritical fluids;

- processing using ionizing radiations;

- processing using high voltage pulsating electric field;

- processing with ultra-short light pulses;

- processing using UV radiation;

- ultrasound processing;

- processing using magnetic field.

The use of athermal processing technologies has increased due to the growing request for high quality foods that still contain the natural taste and flavor, without chemical additives and preservatives. Between the varied athermal processing technologies, ultrasound has a special potential. Whether used alone or combined with other processing

*Corresponding author: cri_sor2002@yahoo.com 
methods, ultrasound processing technology obtained considerable positive results on the quality of food products, being considered effective. The influence of ultrasound on the food processes is considered to be related by cavitation phenomenon and mass transfer increasing. This technology has been successfully applied within food industry for various processes like freezing, filtration, drying, separation, emulsion, sterilization and extraction. Different research studies have suggested that using ultrasound increases the efficiency of the process and improves the quality of the food [2].

Nowadays, athermal processing technology, like ultrasound, has begun to be considered as an emerging technology for removing food contaminants [3].

The ultrasound waves have a frequency ranging between $20 \mathrm{kHz}$ and $100 \mathrm{MHz}$, propagating through any medium, as a mechanical wave. When a high acoustic force is applied, it leads to the formation, development and implosion of cavitation bubbles in a liquid medium, enhancing various food processes [4, 5].The Ultrasound could be considered an essential technology within the effort to achieve the goal of sustainable "green" chemistry and extraction. Within the chemical and food industry domain, the ultrasound is acquainted for considerably affecting the processing rate of various processes used $[6,7]$. Ultrasound-Assisted Extraction (UAE) works based on the concept of acoustic cavitation that deteriorates the plant matrix cell walls and therefore supports the process of releasing the bioactive compounds [8].Low energy usage (low power or low intensity) implies the application of ultrasound having frequencies above $100 \mathrm{kHz}$ at intensities smaller than $1 \mathrm{~W} / \mathrm{cm}^{-2}$. Applied ultrasound waves, having low intensities, utilizes a low level of power that do not induce chemical or physical modifications within the material it crosses, meaning that it is basically non-destructive.

Ultrasound is also used successfully for non-invasive monitoring of food processing. The most common applications of low frequency ultrasound within the food industry is an analytical technique that provides usefull data regarding the physico-chemical properties of food like composition, structure and physical condition. Ultrasound has the advantage over other classical analytical techniques in that the measurements are fast, non-destructive, accurate, automated and can be performed both, within the laboratory or on the flow line.

Ultrasound waves having high intensities has been used for quite some time to generate emulsions, destroy cells walls and disperse aggregate materials. Other applications have been discovered to have great opportunity for further development, like alteration and conduct of crystallization, liquid food degassing, enzyme inactivation, advanced drying and filtration and induction of oxidation reactions. The benefit of using sound wave energy is achieved through different effects that ultrasound causes within the environment in which it is transmitted.

The physical, chemical and mechanical effects of ultrasound at this level are able to change the properties of the material by generating a huge pressure and a high temperature gradient in the environment in which it propagates. Through the sonication process, the longitudinal waves produced when a sonic wave encounters a liquid environment, create compression regions followed by expansion regions. These pressure regions cause cavities and gas bubbles to appear. During the expansion period, the gas bubbles have a much larger surface area, that enhances the diffusion of the gas, determining the bubbles to expand. It arrives to a point where the supplied ultrasonic energy becomes insufficient to maintain the gaseous phase within the bubble; that is why fast condensation takes place. Condensed molecules collide brutally, causing shock waves, which in turn create regions of raised temperature and pressure, attaining up to $5500{ }^{\circ} \mathrm{C}$ and $50 \mathrm{MPa}$.Cavitations can occure from microemission, being able to increase heat and mass transfer. The capacity of ultrasound to create cavitations is influenced by the properties of the ultrasound wave (frequency, intensity), the characteristics of the product (surface tension, viscosity) and the environment 
conditions (temperature, pressure). In order to obtain cavitation, the ultrasound intensity needed raises appreciably over $100 \mathrm{kHz}$.

Currently, more and more uses of ultrasound within various industrial food applications are reported, such as:

$\checkmark$ non-destructive assessment of inner quality and latent defects for whole fruits and vegetables;

$\checkmark$ improving the monitoring of food production processes by accelerating diffusion;

$\checkmark$ measuring the texture, viscosity and concentration of numerous solid or liquid food products;

$\checkmark$ determining the composition of eggs, meat, fruits, dairy products etc.;

$\checkmark$ measuring the consistency, flow and temperature for monitoring and controlling several processes;

$\checkmark$ improving processes such as: surface cleaning, drying and filtration;

$\checkmark$ inactivation of microorganisms and enzymes;

$\checkmark$ degassing of liquids;

$\checkmark$ acceleration of heat transfer and extractive processes.

From these examples, it is obvious that ultrasound technology has several applications within the food industry and their use will intensify in the future.

\section{Mechanism and applications of ultrasound in food processing}

There are many arguments for using ultrasound in food processing. Nowadays, the food industry is becoming progressively aware of the significance of developing new analytical techniques to investigate complex food materials and to evaluate the characteristics of food during processing; ultrasonic techniques are suitable for these two applications.Ultrasonic instruments can be entirely automated and perform fast and accurate determinations. Ultrasound is not destructive or invasive, it can be adapted for online utilizations and used to analyze optically opaque mediums.

Among various food technologies it can be found many examples of processing where ultrasound can be used. Until lately, ultrasound was used within food technologies mainly for non-invasive analyzes, especially referring to quality evaluation. Applications like these use principles similarly to those developed for medical diagnostics, using low-power and high-frequency ultrasound.The application of these techniques can be exemplified in locating foreign bodies within food, analyzing the size of the drop in emulsions of comestible fats and oils and in determining the degree of crystallization of the drops dispersed within the emulsion.

The relation among the characteristics of food that can be measured ultrasonically (propagation speed, attenuation coefficient and acoustic impedance) and physico-chemical properties (composition, structure and physical condition) is the foundation of ultrasonic analysis. This relation can be determined both, empirically by plotting a calibration curve regarding the characteristic we are interested in measuring ultrasonically, or theoretically using mathematical relations that describe the propagation of ultrasound waves through materials. By measuring the attenuation of an ultrasonic pulse, it has been shown that it can be determined the degree of homogenization for milk fat. The determination of ultrasonic propagation speed in connection with attenuation could be used to appreciate the degree of emulsification in materials alike. Also, it can be determined parameters like the degree of creaminess of a specimen, the movement of solid particles / fats on the surface. Information like that provides details, for instance, on the long-term stability of fruit juices and the stability of emulsions like mayonnaise. The conjunction of measurement of propagation speed and attenuation promises to be a method of assessment of comestible fats and oil and 
to determine the degree of crystallization and melting of droplets dispersed within emulsions.

Lately, food technicians have focused their attention to the use of ultrasound within food processing. First mention can be found in 1927 when, in an article called "The chemical effects of high frequency sound waves", it was stated that the physical, chemical and mechanical impact of ultrasonic waves at this level are able to change the properties of matter (destroy the physical integrity, speeding special chemical responses) by generating a huge pressure and a temperature gradient in the environment in which it propagates.

The applications of high power ultrasound generally depend on complex effects of inducing vibration within the propagation medium, which produces cavitations in biological fluids or tissues. Besides to cavitations, ultrasound is capable of weakening the physical integrity of the material or environment, providing environmental dimensions that are alike those of the ultrasound waves used. One of the applications of ultrasonic power, of major importance used in industry, is cleaning and has proven to be a highly effective technology. Surface cleaning can be applied to a large number of disciplines and utilizations (sensors, filters, substrates, reactors, catalysts and heat exchangers).

Ultrasound is very efficient for in-situ cleaning in addition with chemical treatment and provides the following advantages:

- reduces the consumption of chemicals;

- reduces the time of direct contact of the worker with dangerous chemicals;

- high cleaning speed;

- the ultrasonic activity takes place at the micro level in nature and attains all the sections for a uniform cleaning;

- automated operations and savings in energy expenditure, labor and work area [9].

The potential uses of ultrasound within the food industry are varied. One of the most recent uses of ultrasound within food processing has been in emulsification. Emulsions obtained by using ultrasound are frequently much more stable than the products obtained conventionally. Research studies determined that using ultrasound as an aid in processing can reduce the production time of yogurt by up to $40 \%$. Moreover, sonication reduces the normal dependence of the process on milk source and also improves the consistency and texture of the product. It has been shown also that fish eggs exposed to ultrasound having a frequency of $1 \mathrm{MHz}$ for 35 minutes, three times a day, reduced the incubation time of the Grindel (fish species) from 72 to 60 hours. Also, various reports within the literature imply that treating the seeds before sowing, with ultrasonic, improves crop yield.

One of the incipient uses of ultrasound in biochemistry was to destroy cell walls to release the contents. It was later proven that the ultrasound can activate immobilized enzymes by rising the transport of substrate to enzymes. Regarding enzymes, ultrasound it can also be effective as inhibition method. Chambers revealed that using sonication, the pure pepsin was inactivated, likely as a result of cavitation. The incipient activity of peroxidase, liable for the increasing of brown flavors and pigments, was gradually reduced by $90 \%$ asa a result of applying the ultrasound over three hours.

The use of ultrasound notably increases the extraction of organic compounds included within the body or seeds of the plant. The mechanical action of ultrasound ensures a better penetration of the solvent into cellular materials and improves mass transfer. Supplementary benefits outcome from the destruction of cell walls to ease the release of the contents. Ultrasound treatment increases mass transfer as a result of the microstreaming effect, representing a highly efficient method for extracting sugar. Sonication accelerates the diffusion of sugar, obtaining superior levels of dry matter content and sugar content within the juice. In some cases the use of ultrasound has increased the extraction efficiency at low temperatures obtaining a much purer compound in a reduced amount of time. 
Due to the use ultrasound, the extraction of tea compounds from the leaves has increased by $20 \%$. The authors observed that most of the compounds were extracted in the first 10 minutes. Zayas reported that a large amount of rennin enzyme was obtained from the calf's stomach by using ultrasound. Moreover, the ultrasound extraction activity has been shown to be slightly increased compared to normal technologies. Ultrasound was also used to filtration. Following the use of ultrasound, the moisture content of the sludge was quickly decreased from $50 \%$ to $25 \%$, while usual filtration reached a value of $40 \%$ [9]. Acoustic filtration is used effectively to enhance wastewater filtration from industries, process that is usually considered as a gruesome one [10]. While the optimization of ultrasound velocity within filters is extremely important to avoid its damage [7, 11], ultrasound technology used in conjunction with filters increases filter life through prevention of membrane caking and clogging, allowing continuing cavitation around filter surface [12].

As an example of other application of ultrasound, with highly commercial potential, we can present acoustic drying. Advanced ultrasonic drying can be conducted at low temperatures compared to common methodology, decreasing the possibility of oxidation and deterioration of the product. By using ultrasound the heat transfer between a heated solid surface and a liquid is enhanced with about 30-60\% [9]. Ultrasound used within the drying process accelerates the drying rates for meat, fish, fruits and vegetables. This way, it reduces the drying time, increases the heat and mass transfer rate and preserves the properties of the product [13]. In vacuum drying [14] and freeze drying [15], ultrasound increases the drying ratio by comparison to the convective drying used within conventional methods. The power of ultrasound has proven effective in freezing food, the benefits being quite large. Also, ultrasound is used within the process of freezing fresh food, leading both to the rising of the freezing rate and to the increasing of the frozen products quality. It is also applied to the ice cream manufacturing process by reducing the size of the crystals, preventing surface fouling. Other applications include improving the processes of flavor extraction, filtration, mixing and homogenization. New applications like oxidation of unsaturated oils, aging of alcoholic beverages, hydration of acetylene, decalcification of bones and hydrolysis of esters are under development. Table 1 presents applications of ultrasound within the food industry.

Table 1.Applications of ultrasound within the food industry[9]

\begin{tabular}{|l|l|l|l|l|}
\hline Applications & \multicolumn{1}{|c|}{$\begin{array}{c}\text { Common } \\
\text { methodes }\end{array}$} & $\begin{array}{l}\text { Ultrasound } \\
\text { fundamental }\end{array}$ & \multicolumn{1}{|c|}{ Benefits } & \multicolumn{1}{|c|}{ Produce } \\
\hline Cooking & Oven; steam bath & $\begin{array}{l}\text { Uniform heat } \\
\text { transfer }\end{array}$ & $\begin{array}{l}\text { Short processing time; } \\
\text { improved sensory } \\
\text { qualities and heat transfer }\end{array}$ & Meat; vegetables; \\
\hline $\begin{array}{l}\text { Freezing/ } \\
\text { crystallization }\end{array}$ & $\begin{array}{l}\text { Freezer; } \\
\text { immersion freezer; } \\
\text { by contact }\end{array}$ & $\begin{array}{l}\text { Uniform heat } \\
\text { transfer }\end{array}$ & $\begin{array}{l}\text { Shorter processing time; } \\
\text { smaller crystals, } \\
\text { improved diffusion; rapid } \\
\text { drop in temperature; }\end{array}$ & $\begin{array}{l}\text { Meat; } \\
\text { vegetables;fruits, } \\
\text { dairy products; }\end{array}$ \\
\hline Drying & $\begin{array}{l}\text { Hot gas stream } \\
\text { atomization; spray } \\
\text { freezing }\end{array}$ & $\begin{array}{l}\text { Uniform heat } \\
\text { transfer }\end{array}$ & $\begin{array}{l}\text { Short processing time; } \\
\text { improved sensory } \\
\text { qualities and heat transfer }\end{array}$ & $\begin{array}{l}\text { Dehydrated } \\
\text { products (fruits, } \\
\text { vegetables) }\end{array}$ \\
\hline Filtration & Filters & Vibration & $\begin{array}{l}\text { Shorter processing time; } \\
\text { better filtering }\end{array}$ & Liquids (juices) \\
\hline Destruction of & $\begin{array}{l}\text { Thermal treatment; } \\
\text { chemical; electric; } \\
\text { mechanic. }\end{array}$ & $\begin{array}{l}\text { Cavitation } \\
\text { phenomenon }\end{array}$ & $\begin{array}{l}\text { Shorter processing time; } \\
\text { improved hygiene }\end{array}$ & $\begin{array}{l}\text { Carbonated } \\
\text { beverages; } \\
\text { fermented products }\end{array}$ \\
\hline Emulsification & $\begin{array}{l}\text { Mechanical } \\
\text { treatment }\end{array}$ & $\begin{array}{l}\text { Cavitation } \\
\text { phenomenon }\end{array}$ & Shorter processing time & Emulsions \\
\hline
\end{tabular}




\section{Technical equipment using ultrasound for food processing}

For the decontamination of the external surfaces of some horticultural products (within the process of washing fruits and vegetables), there are various companies that produce installations based on a combined technology, both ultrasound and ozone.

SonoSteam (Denmark) manufactures installations for decontamination of the outer surfaces of berries (Figure 1). In this way an efficient reduction of microorganisms on the surface of the products is achieved, as well as of pathogens: Campylobacter, Salmonella, E. coli, Listeria and other bacteria. Supplementary, SonoSteam is efficient against yeast and fungi.

SonoSteam for berry decontamination is a continuous treatment system with adjustable capacity to be correlated with most production lines. The installationhas an integrated PLC system for complete process control and monitoring during treatment.

SonoSteam treatment is completely safe and complies with the regulations for the use of organic products, as it does not change the chemical composition and does not leave residues on the products.

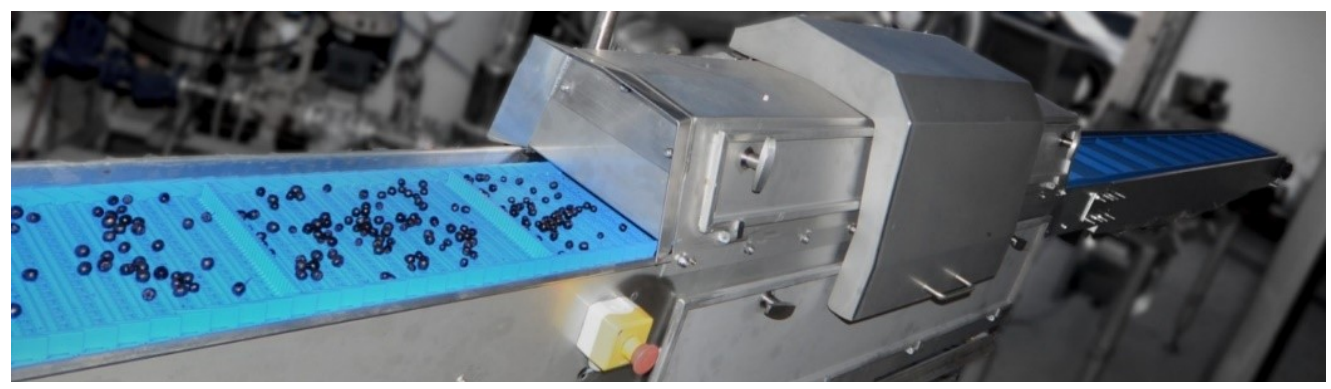

Fig. 1.SonoSteam system [16]

Also, the company produces the MultiMini installation, having multiple possibilities of use (Figure 2).

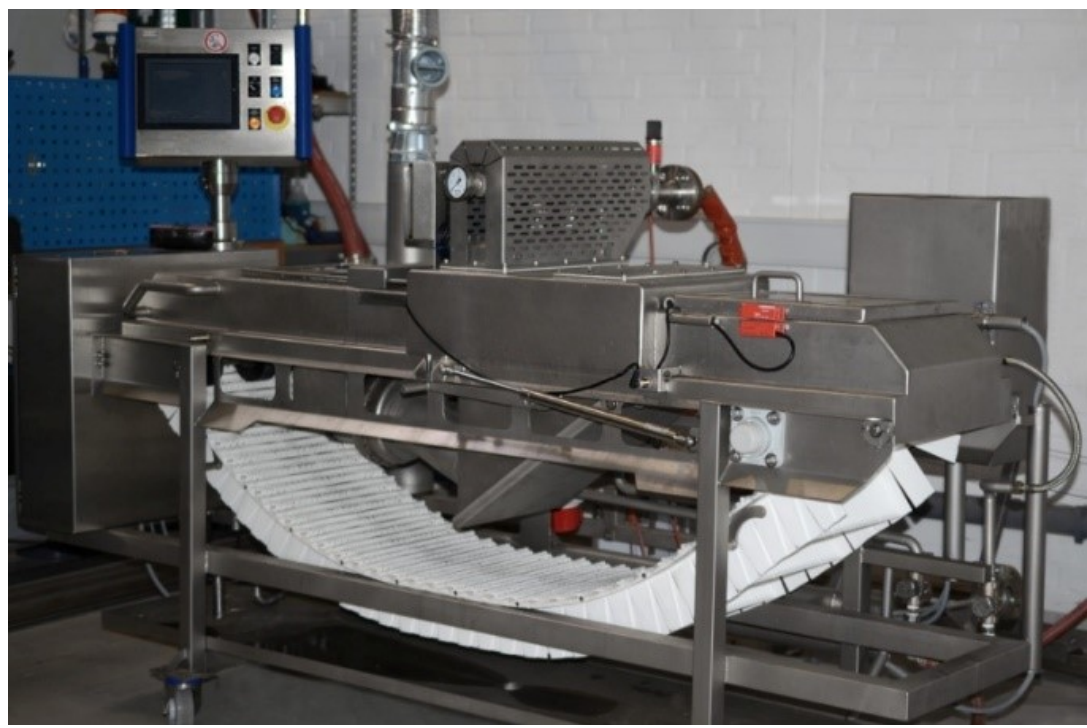

Fig. 2. MultiMinisystem [16] 
The treatment zone is insulated to prevent unreasonable heat formation and to prevent steam consumption. Three nozzles are placed above the conveyor belt and one nozzle is placed below. Every nozzle has a flow rate of approx. 6 grams of steam per second. The great majority of food types and non-food products are processed in only one second, which is frequently enough to achieve a high microbial reduction.

The company R K Transonic (India), produces a range of installations (RKT 1000, RKT 1200 FoodSonic Pro, FoodSonic 600) that use both ozone and ultrasound in the process of washing fruits and vegetables (Figure 3, 4 and 5). Technical characteristics of these installations are presented in Table 2, 3 and 4.

Among the main features of these installations are:

- deep, easy and efficient cleaning: the ultrasonic washing machine uses ultrasound to eliminate $98.9 \%$ of the existing agricultural chemicals from the surface of fruits and vegetables;

- eliminates odor: the container material is endowed with negative ions, that aid to remove disagreeable odors, chlorine and other chemicals;

- silent operation / facile installation: it works using a quiet vibration, without splashing.
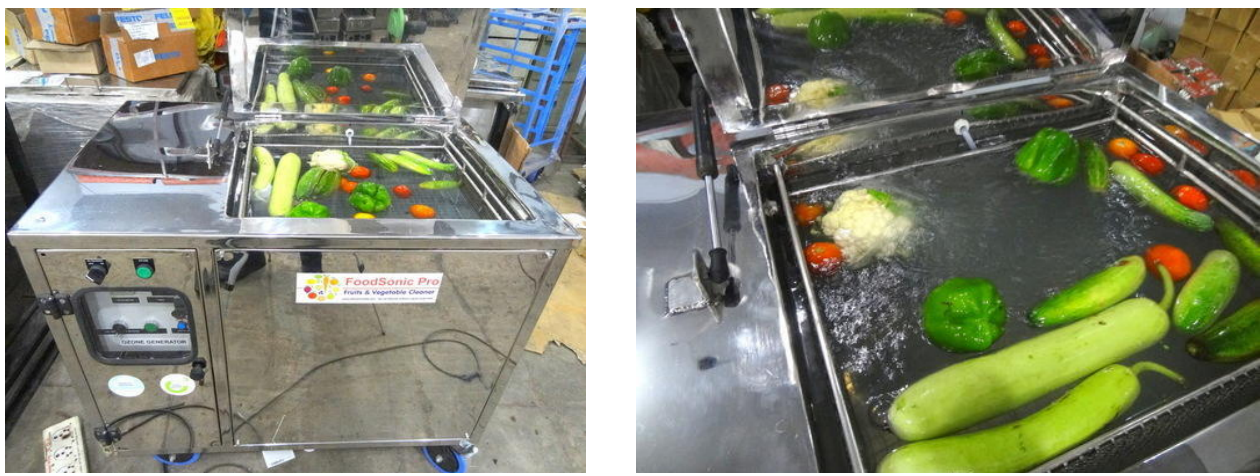

Fig. 3.RKT 1000system[17]

Table 2.Characteristics[17]

\begin{tabular}{|l|c|}
\hline \multicolumn{1}{|c|}{ Characteristic } & Value \\
\hline Frequency & $30 \mathrm{~Hz}$ \\
\hline Model & RKT 1000 \\
\hline Brand & $24 \times 16 \times 16$ inch \\
\hline Container dimensions & 98 liters \\
\hline Useful volume & 15 kg Vegetables/Fruits \\
\hline Load capacity & Stainless steel AISI 316 \\
\hline Container material & $1000 \mathrm{~W}$ \\
\hline Average power & $2000 \mathrm{~W}$ \\
\hline Maximum power & \\
\hline
\end{tabular}




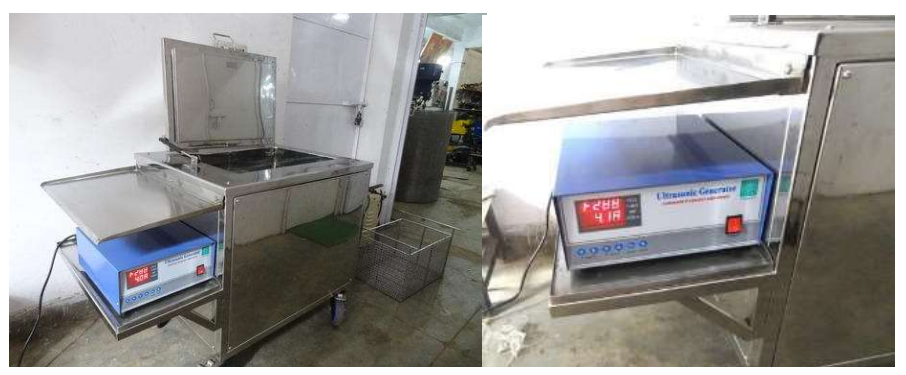

Fig. 4.RKT 1200 FoodSonic Pro system [17]

Table 3.Characteristics[17]

\begin{tabular}{|l|c|}
\hline \multicolumn{1}{|c|}{ Characteristic } & Value \\
\hline Model & RKT 1200 FoodSonic Pro \\
\hline Container material & Stainless steelAISI 316 \\
\hline Container dimensions & $24 \times 16 \times 16$ inch \\
\hline Useful volume & 100 liters \\
\hline Hourly productivity & $100-150 \mathrm{Kgs}$ \\
\hline Load capacity & $10-15 \mathrm{Kg}$ Vegetables/Fruits \\
\hline Average power & $1200 \mathrm{~W}$ \\
\hline Maximum power & $2400 \mathrm{~W}$ \\
\hline
\end{tabular}
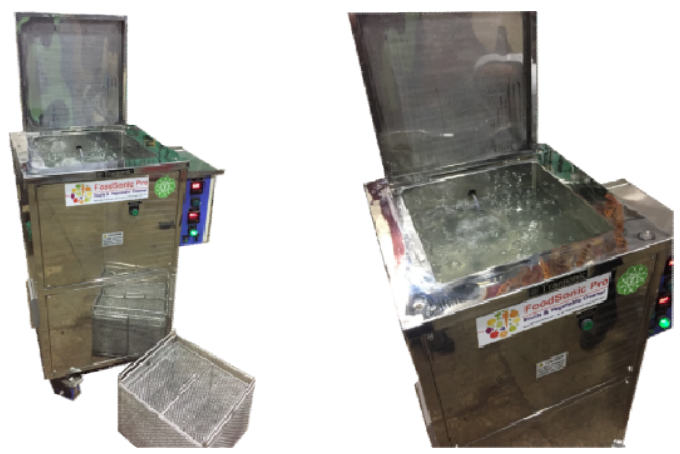

Fig. 5.FoodSonic 600system [17]

Table 4.Characteristics[17]

\begin{tabular}{|l|c|}
\hline Characteristic & Value \\
\hline Model & FoodSonic 600 \\
\hline Use & Vegetable cleaning \\
\hline Dimensions & $15 \times 15 \times 12$ inch \\
\hline Brand & R K Transonic \\
\hline Technology & Ozone + Ultrasound \\
\hline Cleaning capacity & Up to 70 Kg per hour \\
\hline
\end{tabular}




\section{Conclusions}

Minimal processing of foods is defined as a trend to replace classical heat treatment processes with new, athermal processes, including new, milder heat processes.Between the varied athermal processing technologies, ultrasound has a special potential.

The potential uses of ultrasound within the food industry are quite varied, like freezing, filtration, drying, separation, emulsion, sterilization and extraction. Certain advantages of using ultrasound technology within these processes could be summarized as follows:

- when applied to freezing process, it leads both to improve the freezing rate and to enhance the quality of frozen products;

- when applied to sludge filtration, the moisture content of the sludge was quickly decreased from $50 \%$ to $25 \%$, while usual filtration reached a value of $40 \%$;

- when ultrasound is applied within drying process, the heat transfer between a heated solid surface and a liquid is enhanced with about $30-60 \%$;

- when is used to obtain emulsions, the production time is reduced by $40 \%$ and the emulsions are often much more stable than conventionally obtained products;

- when used in combination with ozone, for deep cleaning of fruits and vegetables, it removes almost $99 \%$ of the existing agricultural chemicals from the surface of these products;

- when used within extraction process, it has been shown that the extraction activity is slightly increased compared to normal technologies, sometimes with even $20 \%$.

Also, ultrasound is used successfully in analytical determinations having the advantage, compared to other traditional techniques, that the measurements are fast, non-destructive, accurate, automated and can be performed both, within the laboratory or on the flow line.

This work was supported by a grant of the Ministry of Agriculture and Rural Development on the Sectoral Plan for Research and Development in the field of Agriculture and Rural Development ADER 2022, contract no. ADER 7.5.1.

\section{References}

1. I. Băisan, Preservation of agri-food products, Gheorghe Asachi Technical University of Iași, Faculty of Mechanics, Course, (2018);

2. M. Singla, N. Sit, Application of ultrasound in combination with other technologies in food processing: A review, Ultrasonics Sonochemistry,73, (2021);

3. S. Yuana, C. Li, Y. Zhang, H. Yu, Y. X., Y. Guo, W. Yao, Trends in Food Science \& Technology, Ultrasound as an emerging technology for the elimination of chemical contaminants in food, 109, pp. 374-385, (2021);

4. Y. Tao, D.W. Sun, Enhancement of food processes by ultrasound: a review, Crit. Rev. Food Sci. Nutr., 55 (4), pp. 570-594, (2015);

5. Z. Zhu, Z. Chen, Q. Zhou, D.W. Sun, H. Chen, Y. Zhao, H. Pan, Freezing efficiency and quality attributes as affected by voids in plant tissues during ultrasound-assisted immersion freezing, Food Bioprocess Technol., 11 (9), pp. 1615-1626, (2018);

6. M. Dastkhoon, M. Ghaedi, A. Asfaram, R. Jannesar, F. Sadeghfar, Magnetic based nanocomposite sorbent combination with ultrasound assisted for solid-phase microextraction of Azure II in water samples prior to its determination spectrophotometric, J. Colloid Interface Sci.,513, pp. 240-250, (2018);

7. N. Bhargava, R.S. Mor, K. Kumar, V.S. Sharanagat, Advances in application of ultrasound in food processing: a review, Ultrasonics Sonochemistry, (2020); 
8. B.K. Tiwari, Ultrasound: A clean, green extraction technology, TrAC, Trends Anal. Chem., 71, pp. 100-109, (2015);

9. Project ADER 7.5.1, Research on the application of emerging technologies based on minimal processing methods in the industrialization of horticultural products, Sectoral Plan of the Romanian Ministry of Agriculture and Rural Development (2020);

10. H.M. Kyllönen, P. Pirkonen, M. Nyström, Membrane filtration enhanced by ultrasound: a review, Desalination, 181 (1-3), pp. 319-335, (2005);

11. X. Wen, P. Sui, X. Huang, Exerting ultrasound to control the membrane fouling in filtration of anaerobic activated sludge-mechanism and membrane damage, Water Sci. Technol., 57 (5), pp. 773-779, (2008);

12. M.T. Grossner, J.M. Belovich, D.L. Feke, Transport analysis and model for the performance of an ultrasonically enhanced filtration process, Chem. Eng. Sci., 60 (12), pp. 3233-3238, (2005);

13. S.J. Kowalski, D. Mierzwa, M. Stasiak, Ultrasound-assisted convective drying of apples at different process conditions, Drying Technol., 35 (8), pp. 939-947, (2017);

14. Z.H. Tekin, M. Başlar, S. Karasu, M. Kilicli, Dehydration of green beans using ultrasound-assisted vacuum drying as a novel technique: drying kinetics and quality parameters, J. Food Process. Preserv., 41 (6) (2017), p. e13227, (2017);

15. X.F. Cheng, M. Zhang, B. Adhikari, Effect of ultrasonically induced nucleation on the drying kinetics and physical properties of freeze-dried strawberry, Drying Technol., 32 (15), pp. 1857-1864, (2014);

16. https://sonosteam.com/

17. https://www.ultrasonicindia.com/ 